\title{
Diamond nano-wires, a new approach towards next generation electrochemical gene sensor platforms
}

\author{
C.E. Nebel ${ }^{\mathrm{a}, *}$, N. Yang ${ }^{\mathrm{b}}$, H. Uetsuka ${ }^{\mathrm{b}}$, E. Osawa ${ }^{\mathrm{c}}$, N. Tokuda ${ }^{\mathrm{d}}$, O. Williams ${ }^{\mathrm{e}}$ \\ a Fraunhofer Institute of Applied Solid State Physics, Freiburg 79108, Germany \\ ${ }^{\mathrm{b}}$ Diamond Research Center, AIST, Tsukuba 305-8568, Japan

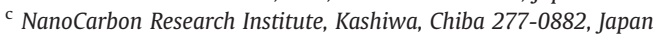 \\ d Nanotechnology Research Institute, AIST, Tsukuba 305-8568, Japan \\ e Instituut voor Materiaalinderzoek, Limburgs Universitair Centrum, Diepenbeek 3590, Belgium
}

\section{A R T I C L E I N F O}

Available online 3 December 2008

\section{Keywords:}

Diamond

Gene-sensor

DNA

Ultra-micro-electrode array

Vertically aligned diamond nanowires

\begin{abstract}
A B S T R A C T
A novel bio-sensing platform is introduced by combination of a) geometrically controlled DNA bonding using vertically aligned diamond nano-wires and $b$ ) the superior electrochemical sensing properties of diamond as transducer material. Ultra-hard vertically aligned diamond nano-wires are electrochemically modified to bond phenyl linker-molecules to their tips which provide mesospacing for DNA molecules on the transducer. The nano-wires are generated by reactive ion etching of metallically boron doped atomically smooth single crystalline CVD diamond. Surface properties are characterized by atomic force, scanning electron and scanning tunneling microcopy. Electro- and bio-chemical sensor properties are investigated using cyclic and differential pulse voltammetry as well as impedance spectroscopy with $\mathrm{Fe}(\mathrm{CN})_{6}^{3-/ 4-}$ as redox mediators which reveal sensitivities of $2 \mathrm{pM}$ on $3 \mathrm{~mm}^{2}$ sensor areas and superior DNA bonding stability over 30 hybridization/ denaturation cycles. The fabrication of "all diamond" ultra-micro-electrode (UME) arrays and multi-gene sensors are discussed taking into account the unique properties of diamond.
\end{abstract}

(c) 2008 Elsevier B.V. All rights reserved.

\section{Introduction}

Nano-wires are new materials, which have characteristics with sometimes extraordinary mechanical, electrical, thermal and multifunctional properties.[1,2] By creating nanostructures; it is possible to control the fundamental properties of materials without change of chemical composition. The attractive world of low dimensional systems, together with the fabrication of functional nanostructured arrays will play a major role in the new trend of chemical and biochemical nanotechnology.[3-5] Nano-wires can be used for tunable transport of electrons with electronic properties strongly influenced by little perturbations on the surface, for giant surface-to-volume ratio enhancements which are important for chemical/bio-chemical applications, and for generation of well defined molecular patterns on bio-sensor surfaces.

Nano-wires are generated by a) self-assembly of small sized structures to form larger structures ("bottom up") or b) by reduction of large systems down to small size ("top-down").[6-8] For biosensing devices, these structures need to offer main advantages over carbon nanotubes (CNTs) which are: 1) Material properties can be

\footnotetext{
* Corresponding author. Tel.: +49 7615159291.

E-mail address: christoph.nebel@iaf.fraunhofer.de (C.E. Nebel).
}

controlled by manipulation of synthesis conditions ("dimensions", "morphology"). 2) Conductivity can be controlled by doping, which allows to fabricate insulating, semiconducting, and metallic wires. 3) The surface of nano-wires can be functionalized to add chemical sensing or bio-sensing properties by use of well established chemistries. [9-13]

Applied materials like $\mathrm{Si}$, [14] $\mathrm{SiO}_{2}$,[15] gold,[16] glassy carbon,[17] $\mathrm{SnO}_{2},[18]$ and $\mathrm{ZnO}_{2}$,[19] do not possess desired chemical stability and reproducibility of bio-chemical surfaces in electrolyte solutions. Only diamond is known to be outstanding with respect to electrochemical properties.[20-22] Its electrochemical background current in phosphate buffer is ten times lower than $\mathrm{Au}$ and about 100 times lower than glassy carbon. Diamond has a wide working window due to large over-potentials for hydrogen and oxygen evolution. A typical window of 3.25 V or greater is normal for high-quality films. Diamond can be nand p-type doped from insulating to semiconducting to metallic, thereby changing from transparent (optical gap of $5.47 \mathrm{eV}$ ) to black. The surface of diamond shows unique properties as it can be terminated with hydrogen, with oxygen and $\mathrm{OH}$ which allows optimizing the electronic properties of the solid/electrolyte interface.[23-25] Diamond surfaces are hydrophobic in case of $\mathrm{H}$ termination and hydrophilic for O-termination. In addition, diamond is known to be chemically inert, [20] bio-compatible,[26-28] and 
shows strongest bonding stability to DNA.[15] Diamond is ultra-hard (50-150 GaP) which is promising with respect to mechanical stability of diamond nano-wires. [29]

The realization of diamond nano-wires started already in 1997 by Shiomi [30], who demonstrated for the formation of porous diamond films by reactive ion etching (RIE) using $\mathrm{O}_{2}$. Later in 2000, nanostructured diamond honeycomb films have been prepared [31] by etching through a porous anodic alumina mask, triggering some activities which are summarized in an article of Shenderova et al.[32] Growth induced formation of nano-scale tubular structures have been reported for the first time in 2003, applying a microwave plasma of hydrogen under a bias potential. [33] In 2008, Zou et al. [34] reported about the fabrication of nanopilar arrays using self aligned Au nanodots as etching mask in a bias-assisted reactive ion etching, applying a hydrogen/argon plasma. Although these achievements demonstrate that vertically aligned diamond nano-wires can be fabricated by a variety of methods, no applications in electro- or bio-chemistry have up to now been reported.

In this paper, we introduce and discuss the fabrication of vertically aligned diamond nano-wires from metallically boron doped single crystalline CVD diamond, by use of diamond nano-particles. A topdown procedure is optimized to fabricate diamond nano-wires where firstly atomically flat diamond is grown by homo-epitaxy of metallically (p-type) doped (100) oriented single crystalline diamond on insulating Ib substrates.[35,36] Then (2) a self organized etching mask from nano-diamond particles [37] is deposited on the surface with particles of typical $10 \mathrm{~nm}$ diameter.[38] 3) Reactive ion etching in $\mathrm{O}_{2} / \mathrm{CF}_{4}$ gas mixture is applied to form patterns of vertically aligned diamond nano-wires. 4) These wires are functionalized by use of an electrochemical phenyl-linker molecule attachment schema,[39-41] which preferentially bonds phenyl linker-molecules to tips of wires. Such functionalized nano-wires are used to bond geometrically controlled oligonucleotide molecules to diamond, thereby combining the outstanding electrochemical properties of diamond as transducer with the advantages coming by dispersed and controlled bonding "like in aqueous solution" of DNA molecules. Sensing properties of this new gene-sensor platform are characterized in detail with respect to sensitivity and chemical stability using cyclic (CV) and differential pulse voltammetry (DPV), and impedance spectroscopy (IMP). Finally, ultra-micro electrode (UME) arrays from diamond will be introduced, which are extremely robust and suitable for applications in high through-put systems for gene sensing in clinical environments.

\section{Experimental details}

Boron-doped single-crystalline diamond films have been grown homoepitaxially on synthetic (100) oriented Ib diamond substrates with $4 \mathrm{~mm} \times 4 \mathrm{~mm} \times 0.4 \mathrm{~mm}$ size, using microwave plasma-assisted chemical vapor deposition (CVD). Growth parameters are: microwave power $1200 \mathrm{~W}$ which generate a substrate temperature around $900{ }^{\circ} \mathrm{C}$, gas pressure 50 Torr, gas flow $400 \mathrm{sccm}$ with $0.6 \% \mathrm{CH}_{4}$ in $\mathrm{H}_{2}$. $\mathrm{B}_{2} \mathrm{H}_{6}$, as boron source, is mixed in $\mathrm{CH}_{4}$, where the boron/carbon atomic ratio $(\mathrm{B} / \mathrm{C})$ was $16,000 \mathrm{ppm}$. Typically $200 \mathrm{~nm}$ thick films have been grown. The conductivity, $\sigma$, is in the range of $200(\Omega \mathrm{cm})^{-1}$ at $300 \mathrm{~K}$ due to ultra-high doping of diamond with $3 \times 10^{20} \mathrm{~cm}^{-3}$ boron acceptors.

Atomically smooth diamond is wet-chemically cleaned by boiling in a mixture of $\mathrm{H}_{2} \mathrm{SO}_{4}$ and $\mathrm{HNO}_{3}(3: 1)$ at $200{ }^{\circ} \mathrm{C}$ for $2 \mathrm{~h}$ to remove graphite. Diamond nano-particles which trend to form clusters are dissolved in water by ultra-sonification ( $200 \mathrm{~W}, 20 \mathrm{kHz}, 12 \mathrm{~h}$ ) to form a pseudo-stable suspension.[38] The concentration of this suspension is crucial and pretreatment of diamond powder is affecting the stability of the suspension. The clean diamond surface is immersed into the suspension and nano-diamond particles are seeded on the smooth by ultra-sonification (100 W, 10 min). After dry blowing, reactive ion etching (RIE) for times between $2 \mathrm{~s}$ to $60 \mathrm{~s}$ is applied, with bias power of $100 \mathrm{~W}$ and antenna RF power of $1000 \mathrm{~W}$ in a $\mathrm{RF}(13.56 \mathrm{MHz}$ ) apparatus, with a pressure of $2 \mathrm{~Pa}$, using a gas mixture of $\mathrm{CF}_{4}(3 \%)$ and $\mathrm{O}_{2}(97 \%)$. Washing in $\mathrm{H}_{2} \mathrm{SO}_{4} / \mathrm{HNO}_{3}$ mixture (3:1) at $200{ }^{\circ} \mathrm{C}$ for $2 \mathrm{~h}$ to remove resident nano-diamond particles from diamond surface.

4-nitrobenzene diazonium tetrafluoroborate (97\%) and tetrabutylammonium tetrafluoroborate (NBu4BF4) were purchased from Aldrich (NJ, US). Dehydrated acetonitrile was obtained from Wako (Tokyo, Japan) and its water content is less $50 \mathrm{ppm}$. Other chemicals and organic solvents (Wako, Japan) are of analytical grade and were used without further purification. Aqueous solutions were prepared using deionized water from a Vivendi UHQ grade water system (Millipore, Yamoto Sci. Co., Japan) with a resistively of not less than 18.2 $\mathrm{M} \Omega \mathrm{cm}$ at $25^{\circ} \mathrm{C}$.

Electrochemically induced covalent attachment of nitrophenyl molecules has been performed using an Electrochemical Analyzer 900 (CHI instruments), and a three-electrode configuration with a platinum counter electrode and an $\mathrm{Ag} / \mathrm{Ag}^{+}(0.01 \mathrm{M})$ reference electrode (BAS, Japan). The active area of the boron doped diamond working electrode is about $3 \mathrm{~mm}^{2}$. Electrolyte solution for the reduction of 4-nitrobenzene diazonium tetrafluoroborate is $0.1 \mathrm{M}$ tetrabutylammonium tetrafluoroborate $\left(\mathrm{NBu}_{4} \mathrm{BF}_{4}\right)$ in dehydrated acetonitrile (Wako chemicals, $\mathrm{H}_{2} \mathrm{O}:<50 \mathrm{ppm}$ ). The diazonium salts reduction is performed in a $\mathrm{N}_{2^{-}}$ purged glove-box applying a constant potential of $-0.05 \mathrm{~V}(\mathrm{vs} . \mathrm{Ag} / \mathrm{Ag}+$ ) for $2 \mathrm{~s}$. Nitrophenyl-modified diamond surfaces are then sonicated with acetone and acetonitrile. Subsequently, 4-nitrophenyl groups $\left(-\mathrm{C}_{6} \mathrm{H}_{5} \mathrm{NO}_{2}\right)$ are electrochemically reduced to aminophenyl groups $\left(-\mathrm{C}_{6} \mathrm{H}_{5} \mathrm{NH}_{2}\right)$ in $0.1 \mathrm{M} \mathrm{KCl}$ solution of EtOH- $\mathrm{H}_{2} \mathrm{O}$ solvent.

The amino-phenyl layer is then reacted with $14 \mathrm{nM}$ solution of the heterobifunctional crosslinker sulphosuccinimidyl-4-(N-maleimidomethyl) cyclohexane-1-carboxylate in $0.1 \mathrm{M} \mathrm{pH} 7$ triethanolamine (TEA) buffer for $20 \mathrm{~min}$ at room temperature in a humid chamber. The NHS-ester group in this molecule reacts specifically with the $-\mathrm{NH}_{2}$ groups of the linker molecules to form amide bonds.

The maleimide moiety was then reacted with (2-4) $\mu$ l thiolmodified DNA ( $300 \mu \mathrm{M}$ thiol DNA in $0.1 \mathrm{M} \mathrm{pH} 7$ TEA buffer) by placing the DNA directly onto the surface in a humid chamber and allow to react for $1 \mathrm{~h}$ at room temperature. As marker DNA we used the 23-mere cancer marker cytokeratin 20 (CK20: $5^{\prime}-\mathrm{HS}_{-} \mathrm{C}_{6} \mathrm{H}_{12}-\mathrm{T}_{9}$-CTG TTT TAT GTA GGG TTA GGT CA-3') and as target the complementary sequence $5^{\prime}$ Cy5-TGA CCT AAC CCT ACA TAA AAC AG-3'), where Cy5 indicates the presence of a red fluorescence marker.

For hybridization of DNA, $5 \mu \mathrm{l}$ of SSPE buffer containing complementary DNA was place on the sensor surface for $1 \mathrm{~h}$ at $20^{\circ} \mathrm{C}$ in a humid cell. The density of complementary DNA has been varied from $10 \mu \mathrm{M}$ to $1 \mathrm{pM}$ to investigate sensitivity properties of the sensor. The sensitivity limits have detected in a container using $100 \mu$ of SSPE. After hybridization the samples have been washed in de-ionized water for $1 \mathrm{~h}$ at $37^{\circ} \mathrm{C}$ to remove non-intentional bonded DNA molecules. Stability measurements have been performed using $1 \mu \mathrm{M}$ solutions over extended cycles of hybridization/denaturation treatments.

Denaturation was performed in $8.3 \mathrm{M}$ urea-solution for $30 \mathrm{~min}$ at $37^{\circ} \mathrm{C}$, followed by rinsing in de-ionized water.

Electrochemical experiments on boron doped diamond are performed on areas of $3 \mathrm{~mm}^{2}$ size. Ohmic contacts ( $\mathrm{Ti} / \mathrm{Pt} / \mathrm{Au}$ ) to boron doped diamond are evaporated outside of this area and sealed with silicon rubber:

An Autolab 2667 computer-controlled potentiostat (Ecochemie, Utrecht, The Netherlands) was used for electrochemical experiments. A Picoplus (Molecular Imaging, US) system equipped with atomic force microscopy (AFM) and scanning tunneling microscopy (STM) was employed to characterize topographic properties of diamond in air. For AFM experiments, ULTRASHARP silicon cantilevers NSC18/no Al (Mikero Masch, US) were used with a typical resonant frequency of $75 \mathrm{kHz}$ and a spring constant of $3.5 \mathrm{~N} / \mathrm{m}$. For STM experiments, $\mathrm{Pt}_{0.8} \mathrm{Ir}_{0.2}$ tips (Molecular Imaging, US) were used. 


\section{Results}

To realize from ultra-hard diamond nano-wires over an area of $3 \mathrm{~mm}^{2}$ we firstly grow atomically smooth metallically boron doped (p-type) diamonds by homoepitaxy on $1 \mathrm{~b}$ diamond substrates by use of a micro-wave assisted chemical vapor deposition technique.[35,36] Fig. 1a shows the surface properties as detected by atomic force microscopy (AFM). The root-mean-square (RMS) roughness is $0.8 \AA$. Then, an etching mask from diamond nano-particles is deposited. Diamond nano-particles, as shown in Fig. 1b, can be produced with well defined size and quality.[37] We applied diamond nano-particles of typical 8-10 nm diameter. These particles are dissolved in water by ultra-sonification ( $200 \mathrm{~W}, 20 \mathrm{kHz}, 12 \mathrm{~h}$ ) to form a pseudo-stable suspension.[38] The concentration of this suspension is crucial and pretreatment of diamond powder is affecting the stability of the suspension. Then the diamond plate is immersed into the suspension and sonificated ( $100 \mathrm{~W}, 10 \mathrm{~min}$ ) to seed diamond nano-particles on the diamond surface. The diamond nano-particle layer is dense and depends on suspension quality and time of sonification. Fig. 1c shows a typical layer as prepared and characterized by AFM which reveals a density of about $10^{11} \mathrm{~cm}^{-2}$.

After deposition of nano-particles, reactive ion etching (RIE) in an $\mathrm{O}_{2}(97 \%) / \mathrm{CF}_{4}(3 \%)$ gas mixture is applied for typical times between 2 to $60 \mathrm{~s}$. The diamond etching rate is $10 \AA / \mathrm{s}$. Diamond wires arise where nano-diamond particles have been deposited which act as mask as shown schematically in Fig. 1d (1-4). An example of vertically aligned diamond nano-wires is shown in Fig. 1e. The geometrical properties of wires depend on the size and etching rate of nano-particles used as etching mask and is currently under investigation. The length of wires can be up to several micrometers if for example silicon instead of diamond particles is used. Silicon is more resistant against etching (etching rate $1 \AA / \mathrm{s}$ ), which will be discussed somewhere else.

For bio-sensor applications a wire separation distance of $10 \mathrm{~nm}$ has been selected which will result in a deoxyribonucleic acid (DNA) density of about $10^{12} \mathrm{~cm}^{-2}$ if these wires are used for anchoring DNA molecules. The typical surface morphology after optimized etching and cleaning in a mixture of sulfuric and nitric acid (volume fraction $3: 1,200{ }^{\circ} \mathrm{C}, 1 \mathrm{~h}$ ) as detected by AFM is shown in Fig. 2a (3D plot) and $2 \mathrm{~b}$ (line scan). Wires are about $10 \mathrm{~nm}$ long and separated from each other by a distance of about $10 \mathrm{~nm}$. The geometrical properties of wires vary in detail but the overall geometry resembles the geometrical properties of the nano-particle etching mask, as shown in Fig. 2b. Detailed electrochemical characterization reveals a surface enlargement by a factor two.

To bio-functionalized these wires, an electrochemical modification schema as shown in Fig. 3 has been applied. Details can be found in Ref. [39-41]. Electrochemical attachment has been selected as it gives rise to preferential attachment of phenyl-linker molecules to tips of wires which is schematically shown in Fig. 3a. At the tips the electric field during electrochemical attachment is high, giving rise to preferential current flow through the tips of wires. The attachment of nitrophenyl molecules from diazonium salts has been performed by application of a constant potential of $-50 \mathrm{mV}\left(\mathrm{vs} . \mathrm{Ag} / \mathrm{Ag}^{+}\right.$) for $2 \mathrm{~s}$. The charge as measured during the attachment and during nitro- to amino-phenyl conversion, that is a measure of the number of phenyl molecules bonded to diamond, is decreased by $50 \%$ compared to the a)

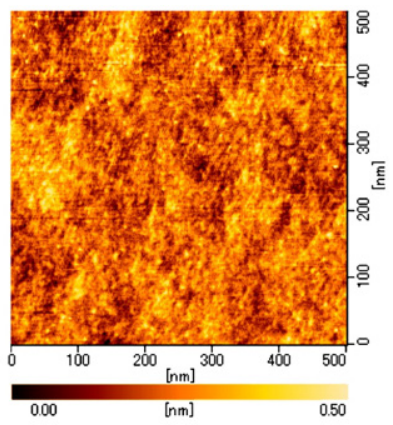

1) Diamond Nano-particle Seeding

d)

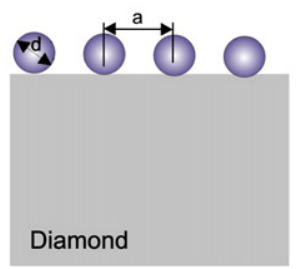

b)

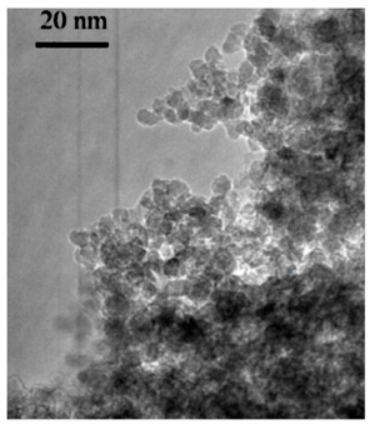

3) RIE ( $>0)$

2) $\operatorname{RIE}(t=0)$

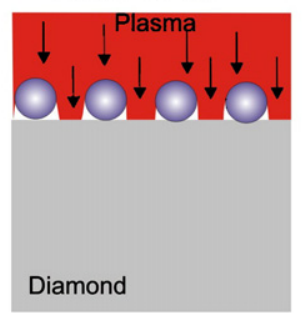

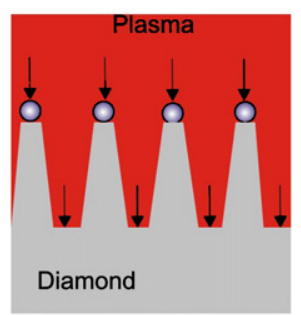

c)

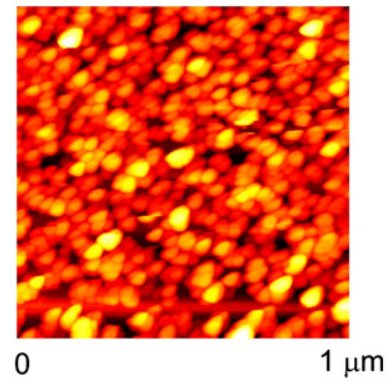

4) Final Surface Structure

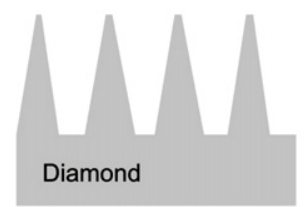

e)

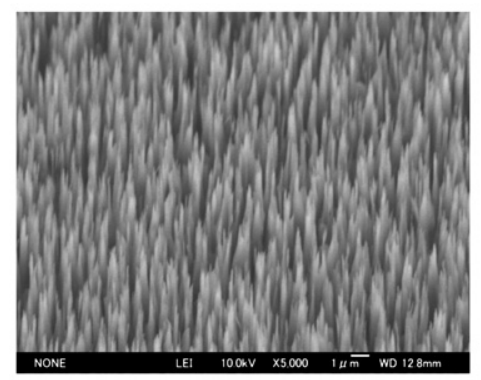

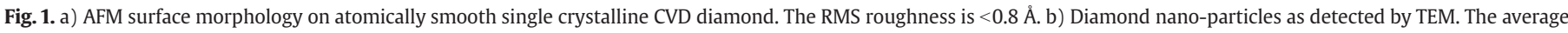

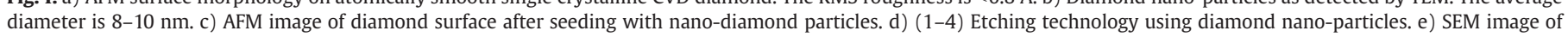
diamond nano-wires. The wires have a diameter of $70 \mathrm{~nm}$ and a length of $700 \mathrm{~nm}$ to $1 \mu \mathrm{M}$. 

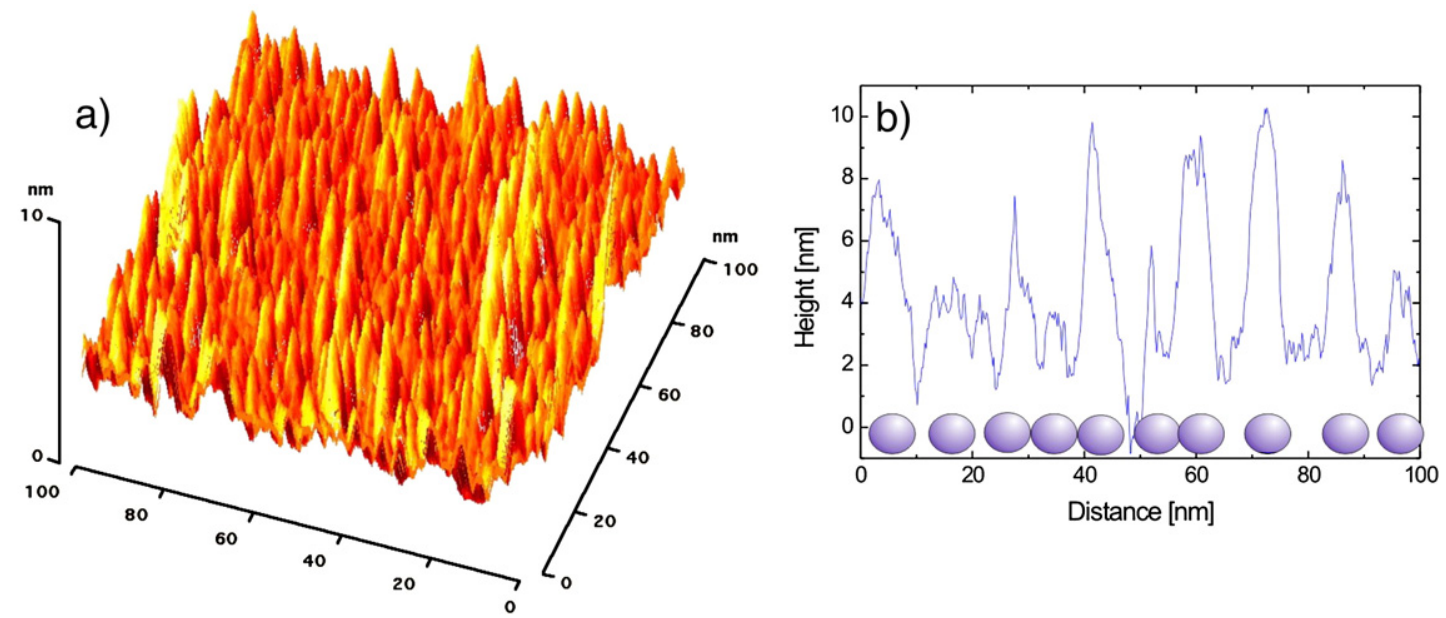

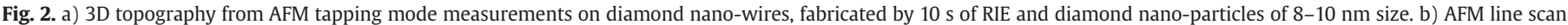
which demonstrates that the wires resemble the geometry of the diamond nano-particles seeded on the surface before RIE etching.

attachment on a smooth diamond surface. This indicates a significantly different bonding schema which we attribute to phenyl bonding to the wire tips.

To elucidate details of phenyl-bonding, we have applied scanning tunneling microscopy (STM) experiments on the nano-wire structure before and after phenyl attachment. Results are shown in Fig. 4a without and $4 \mathrm{~b}$ with phenyl modifications. On clean diamond STM reveals a wire structure with sharp tips. STM images change, however, significantly after phenyl attachment. Phenyl is generating an insulating layer, which causes tunneling currents to decrease. If STM is performed in constant current mode ( $50 \mathrm{pA}$ at $-0.2 \mathrm{~V}$ to diamond), phenyl-coated diamond areas will gives rise to STM tip approach, to establish constant current. The STM deduced surface property results therefore in inverted cone shaped tips (see insets in Fig. 6a,b). Such topographical variations are detected reproducible on phenyl modified diamond nano-wires. It indicates that tips of diamond nano-wires are preferentially modified by this method. The phenyl modified surface fraction is, however, significantly smaller than the total sensor surface, combining now the superior electrochemical properties of diamond with advantages coming from geometrically controlled bonding of linker molecules and later of DNA molecules to the diamond surface.

To attach DNA, the phenyl-layer is then reacted with $14 \mathrm{nM}$ solution of the hetero-bifunctional crosslinker sulphosuccinimidyl-4-(N-maleimidomethyl) cyclohexane-1-carboxylate in $0.1 \mathrm{M} \mathrm{pH} 7$ triethanolamine (TEA) buffer for 20 min at room temperature in a humid chamber which is then exposed to $2-4 \mu$ l thiol-modified DNA ( $300 \mu \mathrm{M}$ thiol DNA in $0.1 \mathrm{M} \mathrm{pH} 7 \mathrm{TEA}$ buffer) by placing the DNA directly onto the surface in a humid chamber and allowed to react for $1 \mathrm{~h}$ at room temperature.

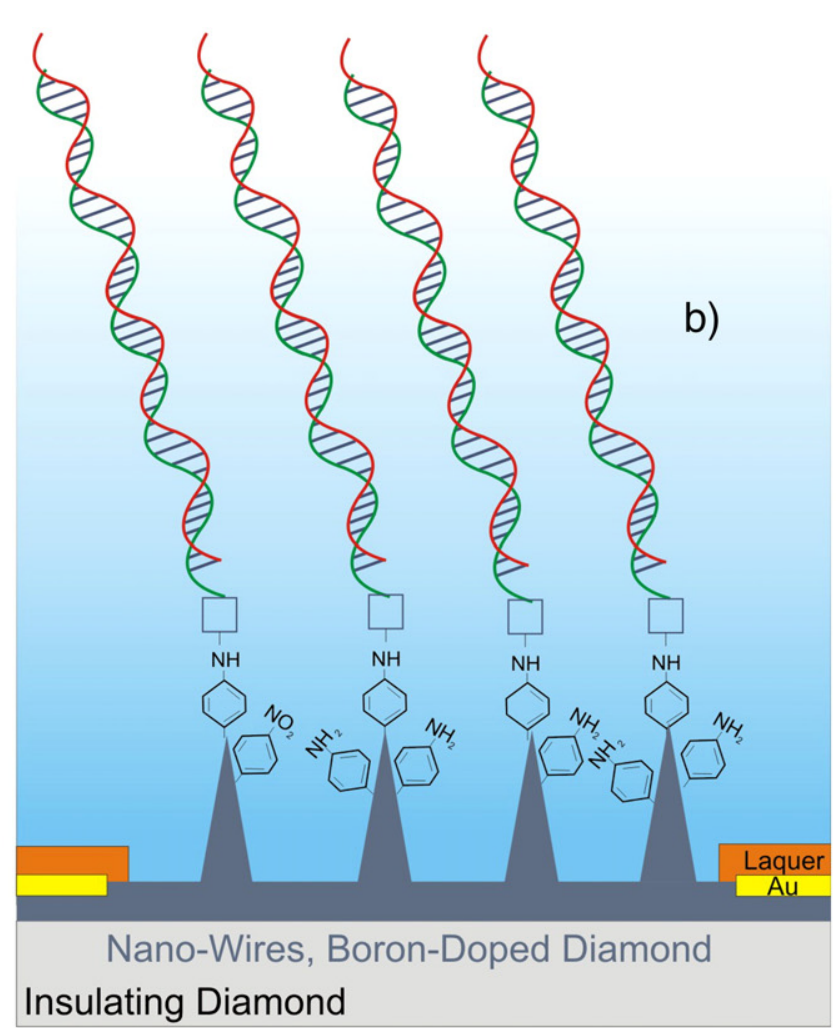

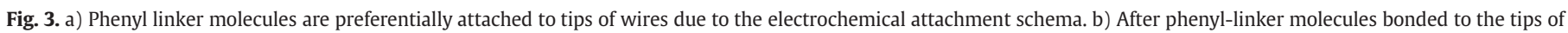
wires, the hetero-bifunctional cross linker and CK20 cancer marker DNA will bond according to the geometrical properties of wires. 


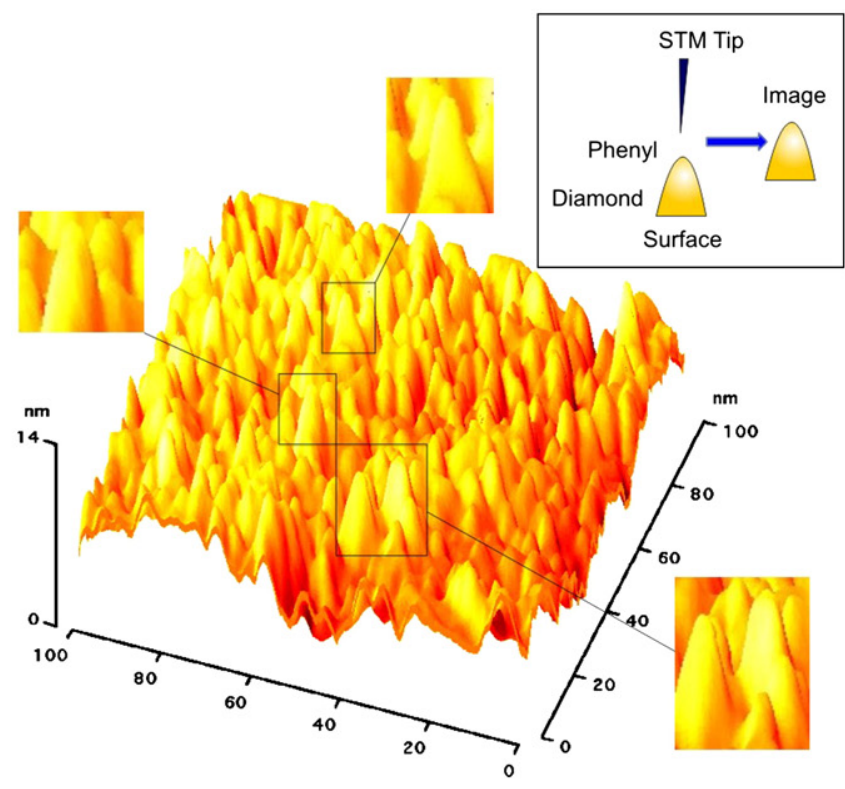

a)

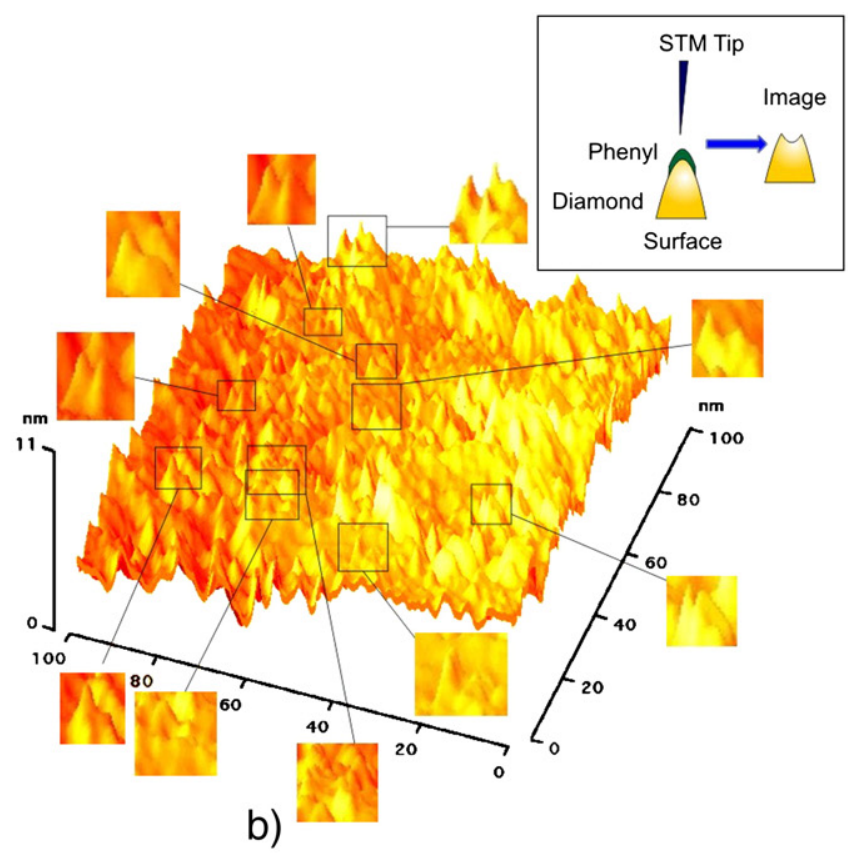

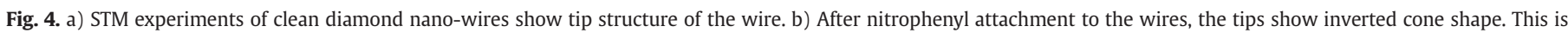
generated by STM experiments and arise by properties shown in insets.

As marker DNA we used the 23-mere cancer marker cytokeratin 20 (CK20:5'-HS- $\mathrm{C}_{6} \mathrm{H}_{12}-\mathrm{T}_{9}$-CTG TTT TAT GTA GGG TTA GGT CA-3') and as target DNA the complementary sequence $\left(5^{\prime}\right.$ Cy5-TGA CCT AAC CCT ACA TAA AAC AG-3', where Cy5 indicates the presence of a fluorescence tag). As DNA self-aligns to cross- and phenyl-linker molecules, a nano-wire tip functionalization takes place, generating dispersed DNA bonding with geometrical properties given by the nano-wire structure (see Fig. 3b).

To investigate the bio-sensing properties of diamond nanowire electrodes we have applied cyclic- (CV) (scan speed $100 \mathrm{mV}$ ) and differential pulse (DPV) voltammetry (scan speed $100 \mathrm{mV} / \mathrm{s}$, pulse height: $2.5 \mathrm{mV}$ ), and impedance spectroscopy in the regime $0.01 \mathrm{~Hz}$ to $10^{6} \mathrm{~Hz}$ at $-0.5 \mathrm{~V}$ (vs. $\mathrm{Ag} / \mathrm{AgCl}$ ), using $1.0 \mathrm{mM} \mathrm{Fe}(\mathrm{CN})_{6}^{3-/ 4-}$ in $5 \mu \mathrm{l}$ phosphate buffer ( $\mathrm{pH}$ 7.4). The active sensor surface area was $3 \mathrm{~mm}^{2}$

Fig. 5a shows a comparison of differential pulse voltammetry signals as applied on bare diamond nano-wires (black line), b) after marker DNA bonding (ss-DNA) (blue line) and after exposure to $10 \mu \mathrm{M}$ of complementary DNA for $1 \mathrm{~h}$ (ds-DNA) (red line. Large DPV amplitudes and variations can be detected. Please note that, using comparable phenyl molecule attachment parameters on smooth diamond surfaces give rise to a significant quenching of the electrochemical response as phenyl tends to form a insulating layer on smooth surfaces, quenching the redox activity of $\mathrm{Fe}(\mathrm{CN})_{6}{ }^{3-/ 4-}$ drastically (will be presented elsewhere). The same problem has been reported for nano-diamond films functionalized with amine groups as linker molecules, followed by cross-linking and DNA bonding which also resulted in a significantly quenched redox signal of $\mathrm{Fe}(\mathrm{CN})_{6}{ }^{3-/ 4-}$. [42]

Typical DPV results as a function of complementary DNA concentration in SSPE buffer during hybridization are shown in Fig. 5b. Complementary target DNA has been diluted from $1 \mu \mathrm{M}$ to $10 \mathrm{pM}$. To identify the sensitivity limit exactly, experiments with 0 to $10 \mathrm{pM}$ of complementary DNA have been performed in $100 \mu \mathrm{l}$ SSPE buffer with otherwise identical parameters. The result is shown in Fig. $5 c$ and indicates a sensitivity limit in the range of $2 \mathrm{pM}$. The chemical stability of DNA molecules bonded to diamond is shown in Fig. 5d. No degradation over 30 cycles of DNA hybridization/denaturation can be detected. The overall perfor- mance of the diamond nano-wire DNA sensor in comparison to published data available in the literature for Au,[43-46] and polycrystalline diamond,[47] using comparable DNA mere structures are shown in Fig. 5e (1:[43], 2:[44], 3:[45], 4:[46], 5:[47]). Sensing by diamond nano-wires is about 100 to 1000 better than using smooth surfaces from $\mathrm{Au}$ and diamond.

The fabrication of ultra-micro-electrode (UEM) electrochemical sensor-arrays is schematically shown in Fig. 6a. It is a monolithic design using undoped diamond as insulating layer and boron doped diamond as electrode. This ensures to keep all advantages which come by use of diamond for electrochemical sensing. In addition, the renewal of sensors after massive use can be achieved simply by wet-chemical cleaning (boiling in $\mathrm{H}_{2} \mathrm{SO}_{4}$ and $\mathrm{HNO}_{3}$ mixtures at $200{ }^{\circ} \mathrm{C}$ for $30 \mathrm{~min}$ ), followed by bio-functionalization processing without the need of sensor or insulator layer replacement.

This technology is well established and involves $\mathrm{SiO}_{\mathrm{x}}$ deposition, photolithography, wet-chemical- or RIE-etching of $\mathrm{SiO}_{x}$, and growth of insulating diamond. For UME-arrays we deposited insulating diamond films of typically $70 \mathrm{~nm}$ thickness on boron doped diamond using standard growth parameters in a microwave assisted CVD chamber. The partial removal of the $\mathrm{SiO}_{\mathrm{x}}$ layer opens access to boron doped conducting sensor spots as shown in Fig. 6a (7) and $6 c$. The insulating diamond layer is highly resistive in the range of $10^{9} \Omega$. The geometrical properties of this sensor array have been chosen with respect to minimization of cross-talk which results in sensor diameters of 5 to 20 micrometer separated from each other by $50 \mu \mathrm{M}$. The dimensions can be reduced easily into the nanometer regime ("ultra-nano-electrodes") by replacement of photolithography by e-beam lithography.

The UME-array has been electrochemically bio-functionalized with DNA as described above. Fig. 6b shows a fluorescence image after DNA hybridization with complementary DNA labeled with the color center Cy5. Each spot appears bright while insulating diamond in between comes out dark. The array consists out of $38 \times 35$ sensor spots. A SEM image (Fig. 6c) reveals some geometrical details. The sensors are $15 \mu \mathrm{M}$ in diameter and separated from each other by $50 \mu \mathrm{M}$. Results of cyclic voltammetry experiments using $\mathrm{Fe}(\mathrm{CN})_{6}^{3-/ 4-}$ before and after UME-array fabrication are shown in Fig. 6b as inset. 
a)
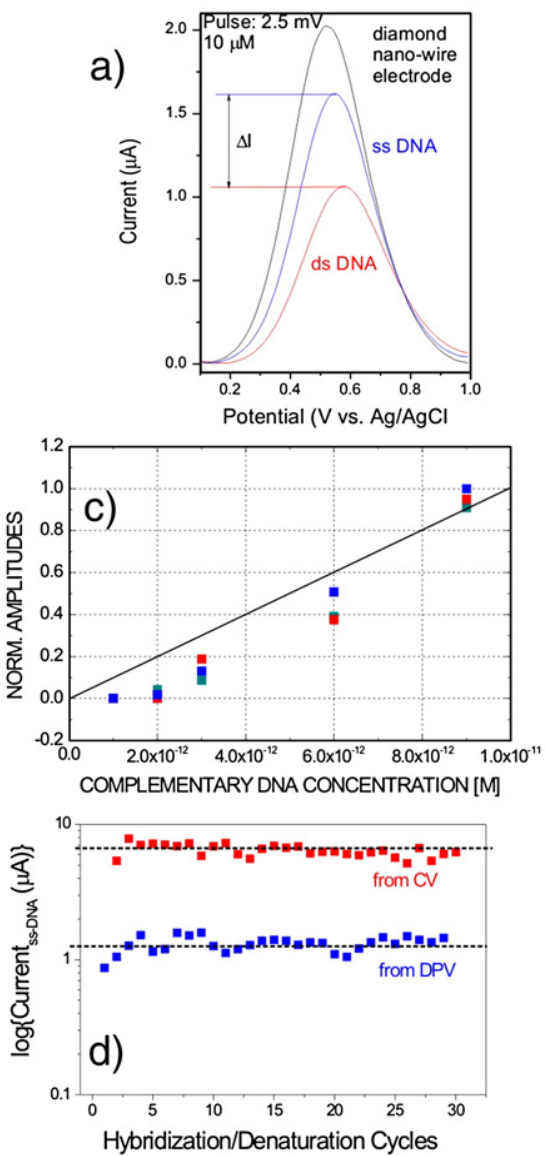

b)
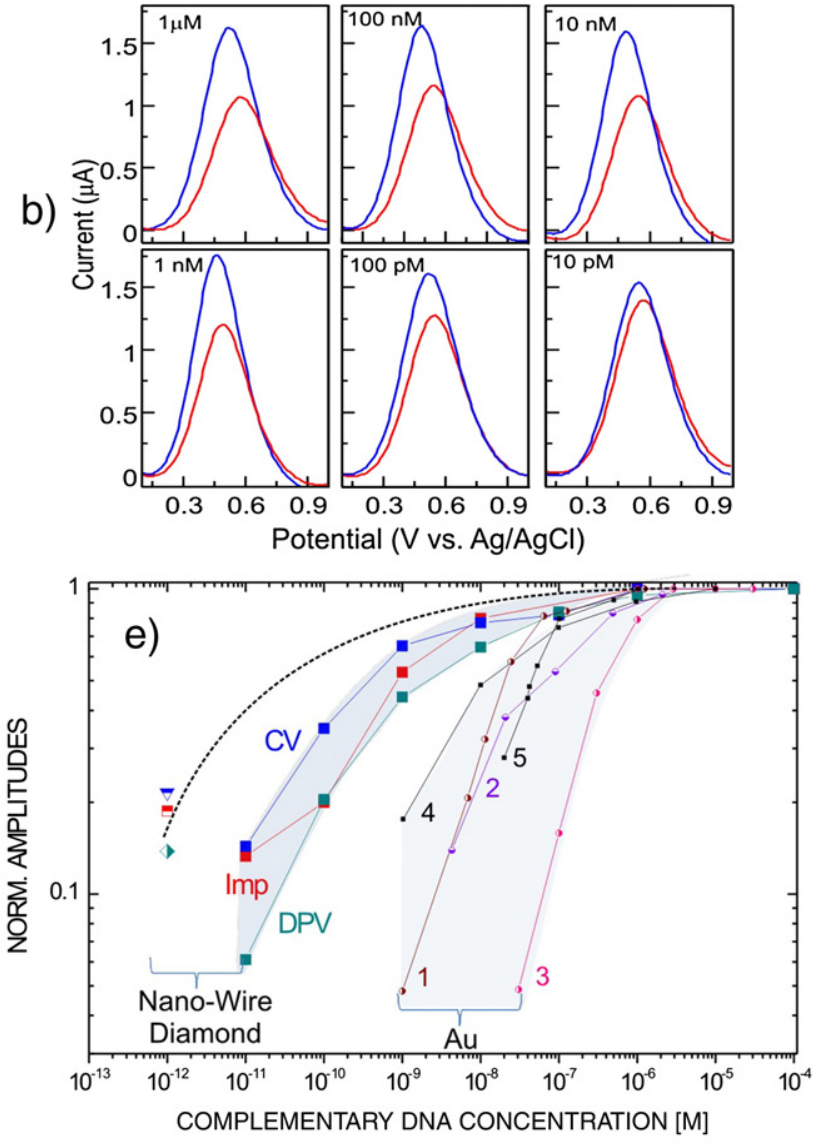

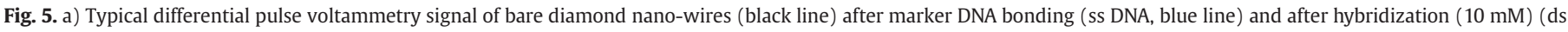

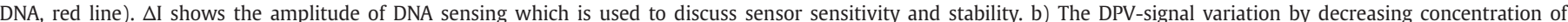

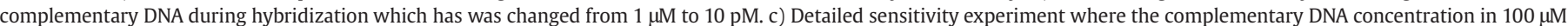

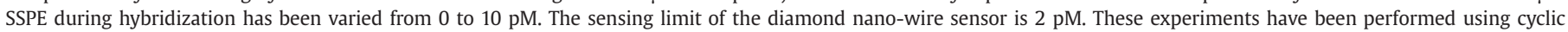

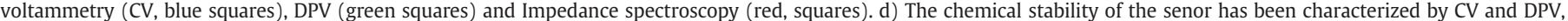

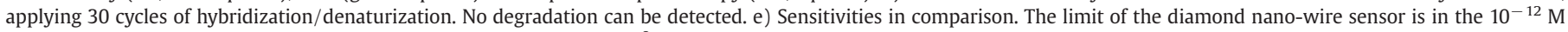

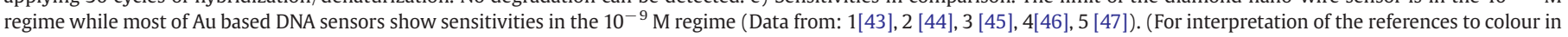
this figure legend, the reader is referred to the web version of this article.)

The cyclic voltammetric current of the UME-array shows sigmoidal current/voltage properties as expected for UME-arrays. [48] Please note, no diamond nano-wires have been generated on these miniaturized sensors up-to-now.

Fig. 6d shows schematically the design of an electrochemical multi-gene sensor. The bonding of different DNA strands to spots can be achieved by individual addressing of spots for electrochemical functionalization, as demonstrated by Yang et al., 2005.[49] Using this technique will allow to bond a variety of different DNA marker molecules to the UME-array without the need to use of micro-fluidics, spotting, or ink-jet printing technologies.[50] It is a simple pathway for fabrication of high-density, highly stable biomolecular arrays for applications in electrochemical biosensors. To read-out each spot individually using redox molecules, intercalation of impedance spectroscopy is however challenging and is currently under investigations.

\section{Discussion and summary}

These results show a new concept towards next generation electrochemical sensor platforms using vertically aligned diamond nano-wires and "all diamond" UME-arrays for sensing. The data show significant improvements with respect to sensitivity and chemical stability required to meet future needs in various fields. The sensitivity of pico-Mole achieved on such macroscopic sensor areas is promising with respect to miniaturization. Decreasing the sensor area from square millimeter to square micrometer will improve the sensitivity by a factor $10^{6}$ atto-mole). Although detailed electronic characterization of diamond nano-wires have not yet been performed, it is very likely that these structures resemble mesoscopic properties as known from other material where single molecular sensing has been achieved.[51] In addition, mesospacing of DNA molecules will improve single-base mismatch discrimination which has been demonstrated on these structures and will be discussed in detail somewhere else. In this paper sensing was focused on the use of $\mathrm{Fe}(\mathrm{CN})_{6}{ }^{3-/ 4-}$ as mediator redox molecule. However, other concepts like redox labeled marker DNA attachment and intercalation are currently under investigations (for a review see Drummond et al. [52]).

We introduce a technological pathway for device miniaturization using "diamond only" as approach to maintain the major advantages of diamond for sensing like hardness, chemical stability and biocompatibility. Diamond nano-wires will survive in harsh environments where other materials like $\mathrm{ZnO}_{2}, \mathrm{SnO}_{2}$ and Si wires fail. Biosensors from diamond can be renewed after deterioration of sensitivity, simply by application of a new cycle of chemical cleaning and chemical functionalization without the need to go through a full solid-state sensor production. Such robust devices will perfectly suit demands in high through-put systems of clinical environments. 
a)
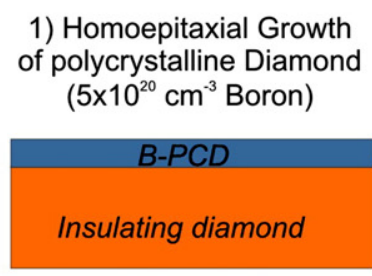

2) $\mathrm{SiO}_{x}$ deposition

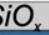

$B-P C D$

Insulating diamond
3) Photoresist (PR) deposition and Lithography

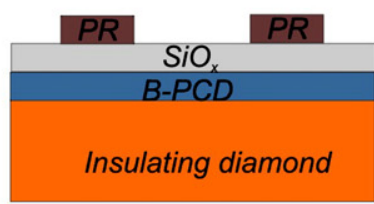

4) Local $\mathrm{SiO}_{2}$ removal

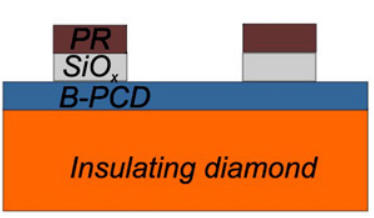

5) RIE

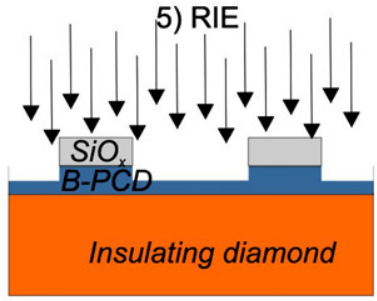

6) Deposition of insulating diamond

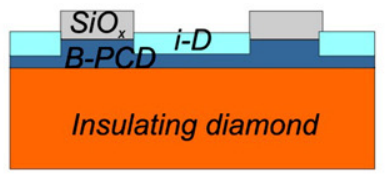

7) Removal of $\mathrm{SiO} 2$

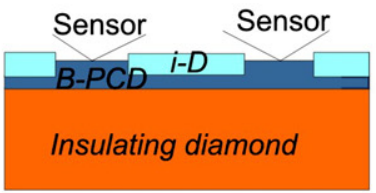

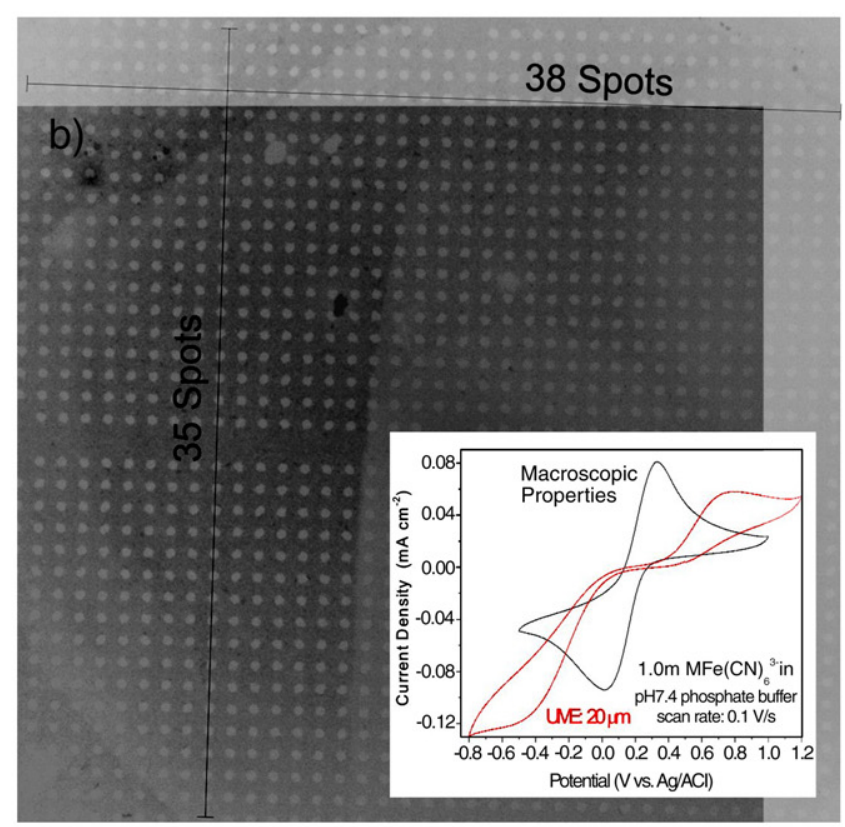

c)
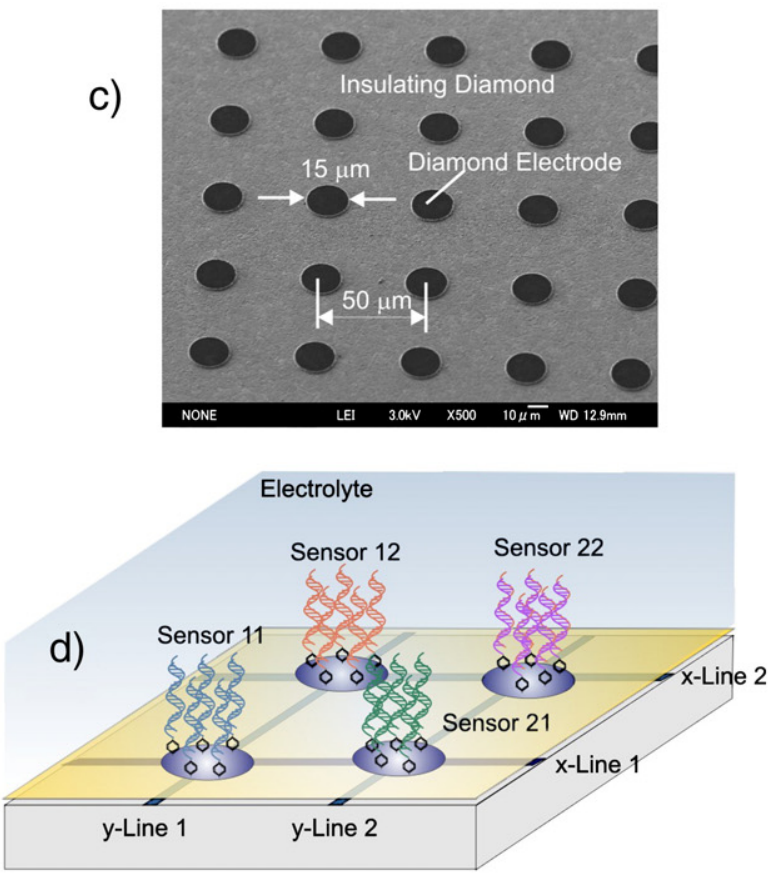

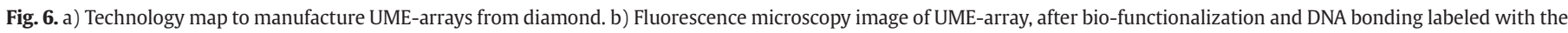

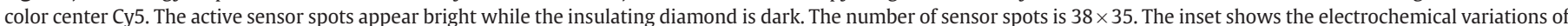

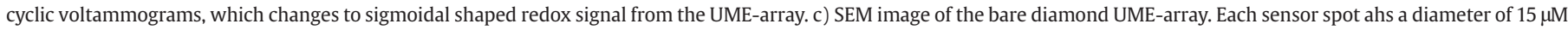

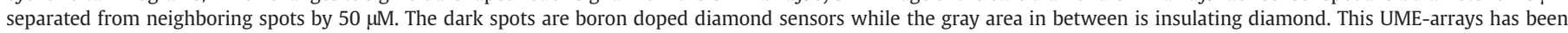

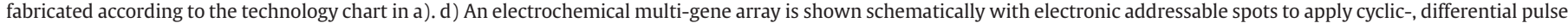
voltammetry or impedance spectroscopy for read-out.

In this paper, the application of diamond nano-wires for biochemical sensing is introduced and discussed to define a "novel" electrochemical bonding schema for geometrically controlled bonding of bio-molecules to a transducer. We introduce wires for controlled bonding of DNA molecules to diamond, a concept which combines the outstanding electrochemical properties of diamond as transducer with the advantages coming by dispersed and controlled bonding "like in aqueous solution" of DNA molecules. The geometrical, electronic, optical and electrochemical properties of these wires need to be characterized in detail in the future to establish better reproducibility with respect to size and length of wires, chemical surface modifications and electrochemical applications and to establish this "new material" for gas- chemical- and bio-chemical sensing. To improve sensing quality further, especially surface defects generated by RIE etching need to be characterized and removed by optimized surface terminations (hydrogen or $\mathrm{OH}$ ) and treatments. Achieving this in combination with miniaturization and multi-array/multi-gene applications will significantly contribute to the development of electronic bio-sensing, required to establish these devices in laboratories and clinical environments. We are confident that diamond nano-wires will become a major player in this field.

\section{References}

[1] G. Zheng, F. Patolsky, Y. Cui, W.U. Wang, C.M. Lieber, Nat. Biotechnol. 23 (2005) 1294

[2] Y. Cui, Q.W. Wei, H. Park, C.M. Lieber, Science 293 (2001) 1289.

[3] I.J. Kim, S.D. Han, C.H. Han, J. Gwak, H.D. Lee, J.S. Wang, Sensors 6 (2006) 526.

[4] M.E.G. Lyons, G.P. Keeley, Sensors 6 (2006) 1791.

[5] W. Liang, Y. Zhuobin, Sensors 3 (2003) 544.

[6] S. Li, P. He, J. Dong, Z. Guo, L. Dai, J. Am. Chem. Soc. 127 (2005) 14, doi:10.1021/ ja0446045; PubMed 15631425.

[7] A. Vaseashta, D. Dimova-Malinovska, Sci. Technol. Adv. Mater. 6 (2005) 312.

[8] X.L. Zhang, J.X. Wang, Z. Wang, S.C. Wang, Sensors 5 (2005) 580.

[9] L. Qian, X. Yang, Talanta 68 (2006) 721.

[10] J. Wang, G. Chen, M.P. Chatrathi, M. Musameh, Anal. Chem. 76 (2004) 298 
[11] J.A. Streifer, H. Kim, B.M. Nichols, R.J. Hamers, Nanotechnology 16 (2005) 1686.

[12] K.M. Metz, K.Y. Tse, S.E. Baker, E.C. Landis, R.J. Hamers, Chem. Mater. 18 (2006) 5398.

[13] U. Yogeswaran, S.M. Chen, Sensors 8 (2008) 290

[14] T. Strother, W. Cai, X.S. Zhao, R.J. Hamers, L.M. Smith, J. Am. Chem. Soc. 122 (6) (2000) 1205

[15] W. Yang, O. Auciello, J.E. Butler, W. Cai, J.A. Carlisle, J.E. Gerbi, D.M. Gruen, T Knickerbocker, T.L. Lasseter, J.N. Russell Jr, L.M. Smith, R.J. Hamers, Nat. Mater. (2002) 253

[16] K. Hashimoto, K. Ito, Y. Ishimori, Anal. Chem. 66 (21) (1994) 3830.

[17] K.M. Millan, A.J. Spurmanis, S.R. Mikkelsen, Electroanalysis 4 (10) (1992) 929.

[18] F.J. Yusta, M.L. Hitchman, S.H. Shamlian, J. Mater. Chem. 7 (8) (1997) 1421

[19] S.S.A. Elrehim, S.M.A. Elwahab, E.E. Fouad, H.H. Hassan, Wekst. Korros.-Mater. Corros. 46 (11) (1995) 633.

[20] J.C. Angus, Y.V. Pleskov, S.C. Eaton, in: C.E. Nebel, J. Ristein (Eds.), Thin Film Diamond II, Semiconductors and Semimetals, vol. 77, Elsevier Academic Press, 2004, p. 97.

[21] G.M. Swain, in: C.E. Nebel, J. Ristein (Eds.), Thin Film Diamond II, Semiconductors and Semimetals, vol. 77, Elsevier Academic Press, 2004, p. 121.

[22] C.E. Nebel, B. Rezek, D. Shin, H. Uetsuka, N. Yang, J. Phys. D: Appl. Phys. 40 (2007) 6443.

[23] J.B. Cui, J. Ristein, L. Ley, Phys. Rev. Lett. 81 (2) (1998) 429

[24] J. Ristein, M. Riedel, L. Ley, J. Electrochem. Soc. 151 (2004) E315.

[25] C.E. Nebel, Science 318 (5855) (2007) 1391.

[26] L. Tang, C. Tsai, W.W. Gerberich, L. Kruckeberg, D.R. Kania, Biomaterials 16 (6) (1995) 483.

[27] H.J. Mathieu, Surf. Interface Anal. 32 (2001) 3.

[28] K.F. Chong, K.P. Loh, S.R.K. Vedula, C.T. Lim, H. Sternschulte, D. Steinmueller, F.S Sheu, Y.L. Zhong, Langmuir 23 (2007) 5615

[29] V. Blank, M. Popov, G. Pivovarov, N. Lvova, K. Gogolinsky, V. Reshetov, Diamond Relat. Mater. 7 (2-5) (1998) 427.

[30] H. Shiomi, Jpn. J. Appl. Phys. 36 (1997) 7745.

[31] H. Masuda, M. Watanabe, K. Yasui, D. Tryk, T. Rao, A. Fujishima, Adv. Mater. 12 (2000) 444.
[32] O.A. Shenderiva, C.W. Padgett, Z. Hu, D.W. Brenner, J. Vac. Sci. Technol. B 23 (6) (2005) 2457.

[33] K. Kobashi, T. Tachibana, Y. Yokota, N. Kawakami, K. Hayashi, K. Yamamoto, Y. Koga, S. Fujiwara, Y. Gotoh, H. Nakahara, H. Tsuji, J. Ishikawa, F.A. Köck, R.J. Nemanich, J. Mater. Res. 18 (2003) 305.

[34] Y.S. Zou, Y. TYang, W.J. Zhang, Y.M. Chong, B. He, I. Bello, S.T. Lee, Appl. Phys. Lett. 92 (2008) 053105 (1-3).

[35] N. Tokuda, H. Umezawa, T. Saito, K. Yamabe, H. Okushi, S. Yamasaki, Diamond Relat. Mater. 16 (4-7) (2007) 767.

[36] N. Tokuda, H. Umezawa, K. Yamabe, H. Okushi, S. Yamasaki, Jpn. J. Appl. Phys. Part 1, $46(4 \mathrm{~A})(2007) 1469$.

[37] A. Kruger, F. Kataoka, M. Ozawa, T. Fujino, Y. Suzuki, A.E. Aleksenskii, A.Y. Vul, E. Osawa, Carbon 43 (8) (2005) 1722.

[38] O. Williams, M. Nesladek, Phys. Status Solidi A 203 (13) (2006) 3375

[39] H. Uetsuka, D. Shin, N. Tokuda, K. Saeki, C.E. Nebel, Langmuir 23 (2007) 3466.

[40] C.E. Nebel, D. Shin, B. Rezek, N. Tokuda, H. Uetsuka, H. Watanabe, J. R. Soc. Interface 4 (2007) 439.

[41] D. Shin, N. Tokuda, B. Rezek, C.E. Nebel, Electrochem Commun. 8 (5) (2006) 844.

[42] W. Yang, J.E. Butler, J.N. Russell Jr, R.J. Hamers, Langmuir 20 (2004) 6778

[43] G. Carpini, F. Lucarelli, G. Marrazza, M. Mascini, Biosens. Bioelectron. 20 (2004) 167.

[44] O. Paenke, A. Kirbs, F. Lisdat, Biosens. Bioelectron. 22 (2007) 2656

[45] J. Kafka, O. Paenke, B. Abendroth, F. Lisdat, Electrochim. Acta., onine available.

[46] H. Aoki, H. Tao, Analyst 130 (2005) 1478.

[47] H. Gu, X. Su, K.P. Loh, J. Phys. Chem. B 109 (2005) 13611

[48] [48] A.J. Bard, L.R. Faulkner, Electrochemical Methods, Fundamentals and Applications, second ed., Wiley Student Edition, John Wiley \& Sons (ASIA) Pte Ltd, Singapore vol. 129809, p. 186.

[49] W. Yang, S.E. Baker, J.E. Butler, C.S. Lee, J.N. Russell Jr., L. Shang, B. Sun, R.J. Hamers, Chem. Mater. 17 (2005) 938.

[50] M.J. Heller, Annual Rev. Biomed. Eng. 4 (2002) 129.

[51] G. Zheng, F. Patolsky, Y. Cui, W.U. Wang, C.M. Lieber, Nat. Biotechnol. 23 (10) (2005) 1294.

[52] T.G. Drummond, M.G. Hill, J.K. Barton, Nat. Biotechnol. 21 (10) (2003) 1192. 